\title{
Breeding Approaches for Climate Resilience in Maize (Zea mays L.): An Overview
}

\section{Anurag Tripathi' ${ }^{1}$, Rahul Kumar ${ }^{2}$, Suresh Yadav ${ }^{2 *}$, Jeet ram Choudhary², Mukesh Choudhary ${ }^{3}$ and H C Lohithaswa ${ }^{4}$}

${ }^{1}$ Department of Genetics and Plant Breeding, GBPUAT, Pantnagar, Uttarakhand, India

${ }^{2}$ Division of Genetics, Indian Agricultural Research Institute, New Delhi, India

${ }^{3}$ ICAR-Indian Institute of Maize Research, Ludhiana, India

${ }^{4}$ Department of Genetics and Plant Breeding, College of Agriculture, V.C. Farm, Mandya

*Corresponding Author: Suresh Yadav, Division of Genetics, Indian Agricultural Research Institute, New Delhi, India.
Received: August 31, 2020

Published: September 23, 2020

(C) All rights are reserved by Suresh Yadav., et al.

\begin{abstract}
Climate change impacts agriculture in numerous ways including rising average temperatures, rainfall, changes in pests and diseases, rise in atmospheric carbon dioxide, ozone concentrations at ground level and changes in the nutritional quality of certain foods. Therefore, achieving global food security for rising global population under limited arable land is a major challenge in the twenty-first century. Maize plays an ever more vital role in the growth of global grains. Maize being a C4 plant has a high yield potential as witnessed from highest compound annual growth rate over last decade. However, in many countries maize production has been plateaued due to full exploitation of hybrid and manufacturing technologies. Therefore, maize ideotypes with favourable traits architecture need to be developed for increased stress resistance and higher yield under changing climate. In maize abiotic stress such as drought leads to delay in silking that result in an increase in the anthesis-silking interval, which is a major cause of yield losses. Acidic soils also conflict with maize production (Zea mays L.) resulting in yield losses of up to 69\%. In this review, we have discussed the current challenges and different breeding approaches for sustainable maize production under changing climate i.e. climate resilience. With the advent of recent advances in omics approaches including genomics, transcriptomics, proteomics and metabolomics, great opportunity exists for development of elite climate resilient maize cultivars.
\end{abstract}

Keywords: Maize (Zea mays L.); Climate Change; Drought Stress; Heat Stress; Anthesis-Silking Interval; Breeding Approaches

\section{Introduction}

Maize, (Zea mays L.), is grown in developed countries with an area of about 100 million hectares. Around $70 \%$ of total maize production comes from low and low middle-income countries (FAOSTAT, 2014). Maize is gaining popularity day by day and its demand is expected to be doubled by 2050. Maize is cultivated largely under rainfed conditions. Climate change is one of the main constraints in maize production. Uneven rains lead to both drought and flooding. Higher temperatures and low moisture drastically affect the maize production. Vulnerability to these stresses mainly affects small-scale maize farmers, which have limited adaptive capacity. Breeding strategies for adaptation to climate change such as breeding for stress tolerant maize varieties can play important role in mitigating these stresses. Farmers 'adoption of enhanced germplasm was disappointing due to inefficient seed input chains, and farmers' preference for cooking, agronomic, and cultural landraces. Maize landraces have a crucial role to play in adapting to climate change has been underestimated by many scientists. Landraces are the best source for the climate adaptive traits [23]. There is unexploited genetic diversity for novel traits and alleles within the primary gene pool of maize and its wild relatives that can serve as good source for breeding of high yielding and stress-tolerant cultivars. Therefore, utilization of the landraces, available with farmers are crucial for effective breeding of stress tolerant maize varieties 
[35] observed that $1 / 4$ th area of the global maize production is affected by drought. In addition, low soil fertility, pests, and diseases are other important constraints that cause substantial yield and economic loss, confounding the heat and drought stress. Therefore, it is difficult to provide an exact figure on the combined maize yield losses due to these stresses. In many areas, maize yields remain very low and variable between years (FAOSTAT, 2014). The world's population is predicted to reach 9 billion by 2050, with the highest population to increase in developed countries. Therefore, increases in agricultural productivity in favourable areas as well as in rainfed and marginal regions becomes crucial because of less scope for expanding agricultural areas. Based on current trends in Asia's population and food production, the difference between food production and demand is likely to be high by 2025. The food supply will fall far short of future demands at current productivity levels and population growth. Climate change predictions would further intensify the capacity of many maize growing regions to ensure food security and faster economic development. Developing improved germplasm to fulfil future generations' needs in the light of climate change and population growth is of utmost importance [28]. Past experience has shown that using new varieties together with enhanced management options can offset yield losses by up to 40 percent [55]. Development and application of molecular tools in plant breeding began in the early 1980s. Molecular breeding boost plant breeding speed and effectiveness [63]. There are many examples of the use of molecular tools to develop enhanced germplasm with resilience to major abiotic and biotic stress [24,59]. Considering the issue of climate change and the time lag between creating enhanced germplasm and adoption in the fields of farmers, there is an urgent need to recognize potential breeding target environments and minimize uncertainty within climate forecasts to enable both researchers and policy makers to set priorities. The evaluation of germplasm is the main factor in improving maize resilience in mega-environments. As climatic conditions change at specific experimental sites and regions producing maize, it will be necessary to re-assess mega-environments to guide breeders for testing potential germplasm under target environments. CIMMYT 's global maize breeding programs can easily source potentially valuable germplasm from the full spectrum of developing world mega-environments. However, the end-use characteristics, color preferences, and other variables can sometimes prevent the direct replacement of lowland-adapted varieties for mid-elevation megaenvironments that are experiencing heat. Thus, besides being able to source germplasm from mega-environments with conditions similar to those that arise from climate change in their own areas, breeders will need the ability to quickly transfer stress tolerance traits into germplasm preferred by people in the target environment they serve.

\section{Breeding strategies}

\section{Maize landraces}

Landraces are considered as dynamic populations of a cultivated plant with historical origin, distinct identity, often genetically diverse and locally adapted, and linked to a collection of seed selection and field management practices by farmers [20]. Such landraces' structure and dynamics are the product of both natural and human selection [11]. Researchers are also concerned that in the face of technological change, the varieties of farmers will be lost, with modern varieties eventually replacing wholesale landraces [34]. Detailed, ground-level studies $[12,16]$. illustrated both the challenges to local varieties of farmers and their resilience as well.

Maintenance of local maize varieties by farmers may play a very important role in adapting to climate change in the area where maize is grown [12]. Small-scale maize farmers in many parts of the world recycle seed by either saving their seed from past harvest or collecting it from fellow farmers $[6,27]$. The vast majority of these farmers work under rain-fed conditions where climate is one of the most important risk factors in their cropping systems. Landrace populations may also be able to keep up with climate change because of farmer selection of climate-adapted traits among landraces [47]. In addition, wild maize relatives, Tripsacum species, and Teosinte species and subspecies are also a great source of variability for climate adaptive traits [23]. In addition, in the primary gene pool of maize and its wild relatives, there is unexploited genetic diversity for novel traits and alleles that can be used to breed new high yielding and stress tolerant cultivars $[22,37,50]$. Breeding efforts as part of climate change-adaptation strategies are likely to rely heavily on the diverse crop genetic resources developed by farmers over the centuries [17]. Thus, along with the farmers' use of maize landraces; with new adaptive traits, many farmers may be able to acquire improved germplasm. Systematic crop breeding can play important role in developing and disseminating improved varieties with sufficient traits to cope with climate change. The adoption of improved germplasm by small-scale maize farmers has been minimal and, therefore, public and private sector interventions are needed to foster a well-functioning seed system that links formal and informal seed systems to allow farmers to access

Citation: Suresh Yadav., et al. "Breeding Approaches for Climate Resilience in Maize (Zea mays L.): An Overview”. Acta Scientific Agriculture 4.10 (2020): $20-29$. 
climate-adapted seed. The desired result would be a segmented seed field of maize characterized by both (improved) landraces and improved varieties of maize. The public and private sectors would provide the latter, and later by farmers, as they can help to generate seed of landraces for sale or land exchange. The international gene bank at the International Maize and Wheat Improvement Center (CIMMYT) in Mexico holds over 27,500 maize accessions, primarily covering landraces $(24,463 ; 97$ per cent from the Americas and the Caribbean), but also breeding lines, teosinte, Tripsacum sp., and some pools and pre-breeding populations [23]. Landrace populations have a wider plasticity in the range of environments compared with hybrids of maize which has higher yield potential in favourable environment. That is one of the reasons farmers value them so much. The adaptive function is a result of the populations' heterogeneous existence. However, as suggested by climate models, the ability of the landraces to adapt to the rapidly changing climate is a concern. The ex-situ landrace collections contain many materials that evolved during the growing season in environments with a propensity for stress, such as drought, heat, or frost.
Breeding climate resilient maize

There are too many affecting factors to accurately forecast a future maize environment or maize product profile. New diseases and stresses are constantly emerging that throw breeding pipelines off balance. The most effective way to prepare for future environments is to reduce breeding cycle time and deliver improved products in real time. The target traits for climate resilient cultivars include smaller ASI, staygreeness, small tassels, erect leaves and high grain yield (Figure 1).

\section{Methods of breeding}

The various approaches in plant breeding for crop improvement are:

- Conventional and population improvement,

- Ideotype breeding,

- Physiological breeding,

- Distant hybridization,

- Genetic engineering.

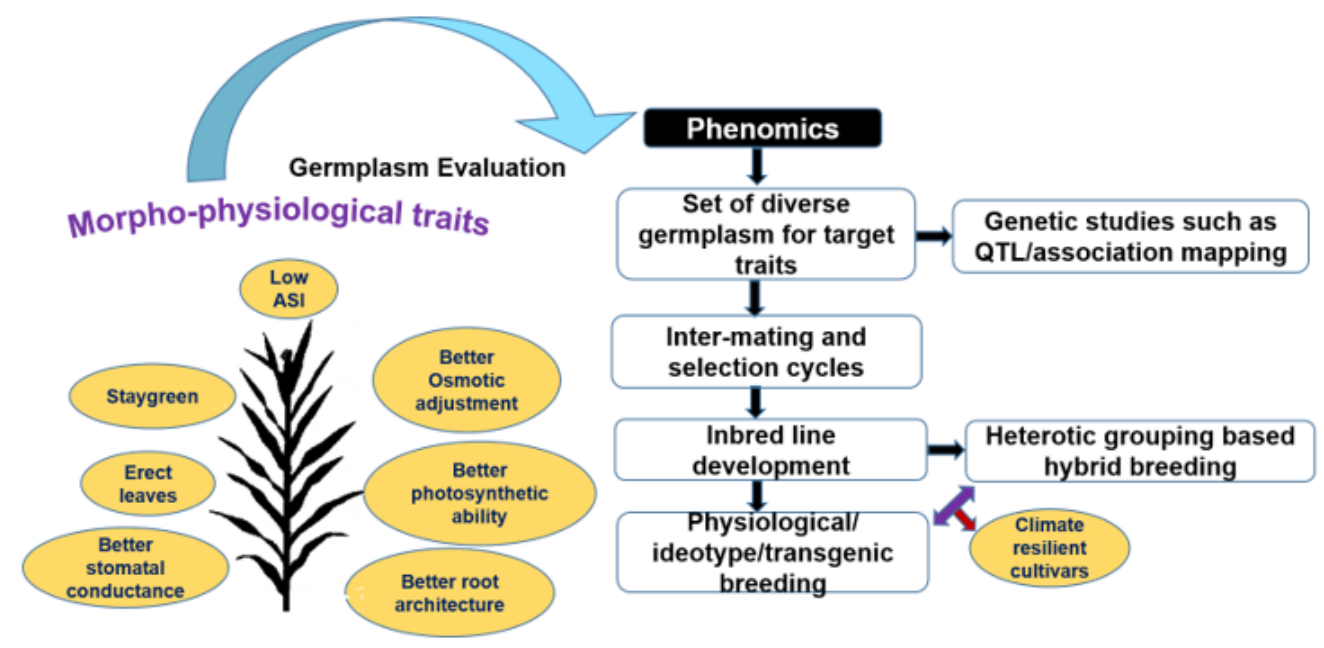

Figure 1: Target traits and breeding approaches for improvement of climate resilience in maize. Precise phenotyping via utilization of phenomics along with integration of conventional, physiological, ideotype and molecular breeding approaches is crucial for achieving higher genetic gains in drought stress breeding programmes

\section{Conventional method}

Maize being a cross pollinated crop exploits the heterosis phenomenon for development of superior hybrids. It involves the development of inbred lines followed by the developed lines for specific combining ability (SCA) and general combining ability (GCA). Then, the developed lines are assigned to different heterotic groups and finally crosses are attempted between lines of different heterotic groups to develop elite hybrids. Other than hybrid development, population improvement is also an effective method for accumulating favourable alleles in the population. Population Improvement was the earliest method used in cross pollinated crops. Accumulation of desirable alleles in a population through various breeding techniques (mass selection or its modification) is known as population improvement.

\section{Methods of population improvement are:}

- Mass selection: Phenotypically superior plants are selected and seeds from them are bulked in order to grow next generation. 
- $\quad$ Recurrent selection: Reselection of plants generation after generation is done with intermating of selected plants to provide opportunity to genetic recombination.

- Simple recurrent selection: A selection procedure which does not include any tester it is; simply known as phenotypic recurrent selection. This method is applied for characters with high heritability.

- Recurrent selection for general combining ability (RSGCA): It is employing to improve the general combining ability of population for a trait with heterozygous tester. It is also known as half sib recurrent selection.

- $\quad$ Recurrent selection for specific combining ability (RSSCA): It is a type of recurrent selection which utilised to improve SCA of a population for a trait using homozygous tester.

- $\quad$ Reciprocal recurrent selection (RRS): This method of recurrent selection used to improve both GCA and SCA of a population for a trait using two homozygous testers. RRS is used to improve two different populations simultaneously for their combing ability. In this each population used as tester for other population.

\section{Ideotype breeding}

It is breeding for a model crop architecture, which is expected to perform best under a well-defined environment. It aims to increase yield potential by manipulating individual traits to their predefined optimum level. It involves the assessment of germplasm for genetic diversity for target traits followed by combining favourable traits via attempting crosses vis a vis selection. Then the developed idiotypes can be tested under multiple diverse environments. The best idiotypes among the tested ones can be released for commercial cultivation.

\section{Physiological breeding}

It is an emerging breeding method that targets the physiological traits for developing cultivars that may perform under wide range of environments. In this breeding method, crosses of the parent with different complex but complementary characters are executed in order to achieve cumulative gene action for yield, while selecting progeny using remote sensing, possibly in combination with genomic selection.

\section{Drought}

It is a worldwide phenomenon that affects $22 \%$ subtropical and $25 \%$ lowland tropical maize. In tropical maize conventional breeding for drought tolerance has resulted in gains of up to $144 \mathrm{~kg}$ $\mathrm{ha}^{-1} \mathrm{yr}^{-1}$ when stress was imposed at flowering stage [30]. Where as in temperate maize breeding progress during mild stress it has been estimated as $73 \mathrm{~kg} \mathrm{ha}^{-1} \mathrm{yr}^{-1}$ and $146 \mathrm{~kg} \mathrm{ha}^{-1} \mathrm{yr}^{-1}$ when the stress was imposed at the flowering stage, and $76 \mathrm{~kg} \mathrm{ha}^{-1} \mathrm{yr}^{-1}$ when the stress was imposed during mid-grain filling stage [21]. In tropical maize drought tolerance breeding success mainly depends on stress screening which occurred during selection of germplasm line [7]. In maize reproductive stage, mainly between tassel emergence and early grain-filling, is the most sensitive to drought stress [33]. During this period if drought occurs then significant reduction in grain yield, along with a reduction in kernel size [15]. Maize susceptibility for drought mainly attributed to its separation of male and female flowers [33]. Drought stress delayed silking. Due to delay in silking result male-female flowering synchrony delayed or increased anthesis-silking interval (ASI). Population improvement approach, mainly applied to increase the frequency of desirable alleles conferring tolerance. Evaluations of maize lines conducted under controlled drought stress which is imposed at flowering for selection of grain yield, increased flowering synchrony and delayed leaf senescence [15]. On an average there is 15 to $30 \%$ yield reduction due to drought stress in maize. Studies reveals that eight cycles of full-sib recurrent selection the drought tolerance in maize was improved. Ideotype breeding for drought tolerance is also effective. Recently many new to ols for phenotyping which is based on remote sensing now available which is non-destructive measurements of growth-related parameters based on spectral reflectance [45]. and infrared thermometry is also important to estimate plant water status (Jones., et al. 2009). Oxygen isotope enrichment $\left(\Delta^{18} 0\right)$ and kernel ash content become new physiological traits to improve maize yields in drought-prone environments $[18,19]$. Both traits involve measurement of physiological traits during the period of crop growth cycle [8], while kernel ash content provides information regarding photosynthetic and re-translocation processes during grain filling [5]. The emerging phenomics tools help in precise characterization and identification of drought tolerant donor parents [10].

\section{Heat}

At the end of this century, temperatures reaches their extreme that never recorded in past century [10]. In maize crop production it has been seen that every $6^{\circ} \mathrm{C}$ increase in temperature during the grain filling period $10 \%$ yield loss is recorded [55]. In some recent studies data from eight-year yield trial of 20,000 maize lines in Africa shows that for every degree above $30^{\circ} \mathrm{C}$ temperature grain 
yield was reduced by 2 percentages [42]. These reports highlight the need to incorporate tolerance to heat stress into maize germplasm. However, relatively little research has been conducted on heat stress compared to other abiotic stresses in maize. Heat stress can be defined as when temperatures raises above a threshold level that result in irreversible damage to crop growth and development. Heat stress is a function of intensity, duration and the rate of increase in temperature. Furthermore, different plant tissues and organs, and different developmental stages are affected by heat stress in different ways, depending on the susceptibility of the different dominant metabolic processes that are active at the time of stress [40]. Accumulated high temperatures can cause an array of morphological, anatomical, physiological and biochemical changes within maize. The most significant factors associated with maize yield reduction include shortened life cycle, reduced light interception and increased sterility [54]. To stabilize maize yields under elevated temperatures it is necessary to understand the mechanisms responsible for yield loss.

In reproductive organ damage caused by heat stress is lower compared to other organ [54]. For successful grain set in maize viable pollen and their interception by receptive silks, and male gamete transfer to egg cell is required [51]. In reproductive stage higher temperature cause yield loss due to decrease kernel weight and no of grain count [51]. Actually, heat reduces pollen water potential, quantity of pollen shed pollen tube germination [51]. Even though less water potential pollen is still capable to germination [9], but pollen viability is reduced [51]. The position of tassel also causes its maximum exposure to extreme temperature increases probability of pollen damage due to heat stress. During early stages of kernel development if higher temperature prevails causes detrimental effect on kernel development [38]. Heat stress during kernel development stage mainly affects cell division, sugar metabolism and starch biosynthesis ultimately reducing subsequent dry matter accumulation within kernels [25,30,48]. In some studies, it shows that increase temperature also increases the growth rate of kernel development [53], however, this increase in growth rate of kernel development was unable to compensate the reduction cause by heat stress [53]. D uring grain filling heat stress reduces endosperm starch content which is the major constituent of kernels [24,53]. The effect of heat stress $\left(35^{\circ} \mathrm{C}\right)$ on maize kernel sin capacity in vitro. Normally in maize, maximum seedling growth occurs at a soil temperature $26^{\circ} \mathrm{C}$ but above this temperature both root and shoot mass decrease by $10 \%$ for each degree above $35^{\circ} \mathrm{C}$ [58]. However above $35^{\circ} \mathrm{C}$ temperature in maize reduces the leaf elongation rate, leaf area, shoot biomass and photosynthetic $\mathrm{CO}_{2}$ assimilation rate [61]. In vegetative stage most sensitive process for heat stress is elongation of the first internode and overall shoot growth [62]. Usually $\mathrm{C}_{4}$ required higher optimum temperature for photosynthesis than $\mathrm{C}_{3}$ plants because higher temperature reduce rubisco oxygenase enzyme activity [13].

\section{Wide hybridization (Flooding as case study)}

Crossing between two different species of the same genus or genera of same family is called wide hybridization. Flooding damage in maize is highly dependent on growth stages of plant, soil-air temperatures and length of the flooding period. Maize is affected by flooding in the early stages of development and hence is a major issue for maize growers due to enormous losses in yield and limited accessibility of flooding-tolerant strains. Although a few maize lines were identified to form adventitious roots at the soil surface during trial flooding conditions [44] teosintes found from regions that are known to take frequent rainfall may offer a superior genetic resource for the identification and development of flood-tolerant maize. The teosintes, viz., Z. nicaraguensis $[14,36]$., Z. luxurians and Z. mays ssp. huehuetenangensis [44], have been detected to exhibit a higher capacity for adventitious root formation than some maize inbreds. Z. mays ssp. huehuetenangensis plants were detected to show a high adaptability to flooding by emerging adventitious roots above the soil surface [44]. As a consequence, the adventitious roots of this teosinte can uptake oxygen, and this characteristic may play a vital role in its adaptation to flooding. Similarly, Z. nicaraguensis and Z. luxurians were reported to develop well-formed aerenchyma in adult plants [49] hence, reporting tolerance to flooding.

Genetic Engineering is the deliberate, controlled manipulation of the genes in a plant with the intent of making that plant better in some way. This is usually done independently of the natural reproductive process. The result is a so-called Genetically Modified (GM) or transgenic varieties.

The transgenic lines produced open the way to definitely confirm the physiological role of Zea mays via complementary genetic experiments making use of the $\mathrm{F}_{2}$ maize lines, together with the analysis of the Asr1 (abiotic stress resistance) respective genes' regulatory regions. Yet, the results already obtained are encouraging enough to develop non-GM varieties using the MAS method 
(marker assisted selection) with markers encompassing the Asr1 Io allele, to find better Asr1 allele, in maize biodiversity, and to continue the evaluation and development of Asr1 over-expressing lines. The other results presented in this work appear to confirm that C4-PEPC contributes to the control of carbon flux in the C4 photosynthesis pathway. They also underline the remarkable plasticity and adaptive capacity of maize as illustrated by the pleiotropic response to the genetic modification and the improved photosynthetic performance of the transgenic plants resulting notably in a better water use efficiency and dry matter production under mild drought conditions. More generally, through transgenic modifications in maize, we were able to increase endogenous biochemical activities related to water economy or drought tolerance and opened the way to develop maize varieties more tolerant to dry growing conditions.
Molecular breeding approaches include marker assisted backcrossing (MAB), marker assisted recurrent selection (MARS) and genomic selection (GS) can help in rapid improvement of complex traits like abiotic stresses [24]. The identification of quantitative trait loci (QTLs) via mapping and introgression via MAB (for major QTLs) and MARS (major and minor QTLs) can also be referred as QTLian breeding [3,24], identified six constitutively expressed metaQTLs for grain yield and one metaQTL for ASI under drought stress in maize (Table 1). The list of recently identified QTLs for drought stress tolerance associated traits is given in table 1 . The information of well characterized (phenotypically and genotypically) QTLs can be called as QTLome [52]. Hence, the introgression of well-characterized robust QTLs can help to develop "climate change ready" cultivars [57].

\begin{tabular}{|c|c|c|c|c|c|}
\hline Quantitative Trait Loci & $\begin{array}{l}\text { Mapping Popu- } \\
\text { lation }\end{array}$ & Parents & $\begin{array}{l}\text { Genoty-ping } \\
\text { Markers }\end{array}$ & $\begin{array}{l}\text { Chromo- } \\
\text { some }\end{array}$ & References \\
\hline $\begin{array}{l}145 \text { QTLs (Grain yield, ASI), } 7 \mathrm{mQTL} \\
\text { for grain yield and1 mQTL for ASI }\end{array}$ & \multirow{2}{*}{$\begin{array}{l}\text { RILs } \\
\mathrm{F}_{2: 3} \\
\mathrm{~F}_{2: 3}\end{array}$} & \multirow{2}{*}{$\begin{array}{l}\text { CML444 × MALAWI } \\
\text { CML440 × CML504 } \\
\text { CML444 × CML441 }\end{array}$} & SNPs & $\begin{array}{l}1,2,3,4,5,7 \\
8 \text { and } 10\end{array}$ & $\begin{array}{l}\text { Almeida., et al. } \\
2013\end{array}$ \\
\hline $\begin{array}{l}203 \text { QTLs (ASI, ears per plant, stay- } \\
\text { green and plant-to-ear height ratio) }\end{array}$ & & & SNPs and SSRs & $\begin{array}{l}1,3,4,5,7 \\
\text { and } 10\end{array}$ & $\begin{array}{l}\text { Almeida., et al. } \\
2014\end{array}$ \\
\hline $\begin{array}{l}169 \text { QTLs (Grain yield per plant, ear } \\
\text { length, kernel number per row, ear } \\
\text { weight and hundred kernel weight) }\end{array}$ & NAM & $\begin{array}{l}11 \text { bi-parental families } \\
\text { (2000 RILs) }\end{array}$ & SNPs & 1,3 and 10 & Li., et al. 2016 \\
\hline $\begin{array}{l}12 \text { stable QTLs for tassel primary } \\
\text { branch number and ear number per } \\
\text { plant }\end{array}$ & $\mathrm{F}_{2: 3}$ populations & $\begin{array}{l}\text { Langhuang } \times \text { TS141 } \\
\text { and Chang7-2 } \times \text { TS141 }\end{array}$ & SSRs & $\begin{array}{l}1,2,3,4,5,6 \\
\text { and } 7\end{array}$ & $\begin{array}{l}\text { Zhao., et al. } \\
\qquad 2017\end{array}$ \\
\hline $\begin{array}{l}12 \text { QTLs for ASI, ear weight and num- } \\
\text { ber of kernels per cob }\end{array}$ & 160 RILs & CM123 × CM140 & SSRs & $\begin{array}{l}1,3,4,6,7 \\
\text { and } 9\end{array}$ & Kaur 2017 \\
\hline $\begin{array}{l}167 \text { QTLs for ear length, ear diameter, } \\
\text { ear weight, kernel weight per ear, and } \\
\text { hundred-kernel weight }\end{array}$ & $213 \mathrm{~F}_{2: 3}$ families & H082183 × Lv28 & 55K SNP & $\begin{array}{c}1,2,3,4,5,7 \\
8,9,10\end{array}$ & $\begin{array}{l}\text { Abdelghany., et } \\
\quad \text { al. } 2019\end{array}$ \\
\hline
\end{tabular}

Table 1: List of recent examples of QTLs identified for drought stress tolerance in maize.

\section{Conclusion}

Farmers have a long record of adapting to the impacts of climate variability. However, based on current scientific knowledge, the probably impacts of climate change are out of the range of farmers' previous experiences and represent a greater challenge.
Climate change will, hence, severely test the farmers' resourcefulness [2]. This review focused on technologies for the development of improved germplasm; however, this is only the first step in the process. Adaptation to climate change requires cross-disciplinary solutions that include the development of appropriate germplasm 
and mechanisms to facilitate farmers' access to the germplasm. Seed production and deployment, effective policies and management strategies at the country, regional and international levels will all be required to ensure the technologies reach the intended beneficiaries and make the desired impacts.

Varieties with increased resilience abiotic and biotic stresses will play an important role in Autonomous adaptation to climate change [28,32]. Over fifty years ago scientists were able to offset yield losses by up to $40 \%$ through the development of improved germplasm and management options [31]. Today scientists face an even harder challenge to meet the needs of future generations in the face of both population growth and climate change. While this challenge is immense, the advancement in molecular and phenotyping tools combined with the vast accumulated knowledge on mechanisms responsible for yield loss will provide a solid foundation to achieve increases in productivity within maize systems.

\section{Declaration}

The authors declare that no conflict of interest.

\section{Author's Contribution}

The idea was conceptualized by AT and SY. SY, MC and AT contributed to manuscript preparation. RK, HCL and JRC helped in reviewing of manuscript. All authors approved the manuscript before submission.

\section{Bibliography}

1. Abdelghany M., et al. "QTL analysis for yield-related traits under different water regimes in maize". Maydica 64.2 (2019): 10.

2. Adger WN., et al. Assessment of adaptation practices, management options, constraints and capacity. Climate Change 2007: Impacts, Adaptation and Vulnerability. Contribution of Working Group II to the Forth Assessment Report of the Intergovernmental Panel on Climate Change. Cambridge, UK and New York, USA (2007).

3. Almeida GD., et al. "QTL mapping in three tropical maize populations reveals a set of constitutive and adaptive genomic regions for drought tolerance". Theoretical and Applied Genetics 126 (2013): 583-600.
4. Almeida GD., et al. "Molecular mapping across three populations reveals a QTL hotspot region on chromosome 3 for secondary traits associated with drought tolerance in tropical maize". Molecular Breeding 34.2 (2014): 701-715.

5. Araus JL., et al. "Basis of the relationship between ash content in the flag leaf and carbon isotope discrimination in kernels of durum wheat". Photosynthetica 39 (2001): 591-596.

6. Badstue LB., et al. "Examining the role of collective action in an informal seed system: a case study from the Central Valleys of Oaxaca, Mexico". Human Ecology 34 (2006): 249-273.

7. Banziger M and Diallo AO. "Progress in developing drought and stress tolerant maize cultivars in eastern and southern Africa". Seventh Eastern and Southern Africa Regional Maize Conference, 11th-15th February (2001): 189-194.

8. Barbour MM and Farquhar GD. "Relative humidity and ABAinduced variation in carbon and oxygen isotope ratios of cotton leaves". Plant, Cell and Environment 23 (2001): 473-485.

9. Barnabas B. "Effect of water loss on germination ability of maize (Zea mays L.) pollen”. Annals of Botany 48 (1985): 861864.

10. Battisti DS and RL Naylor. "Historical warnings of future food insecurity with unprecedented seasonal heat". Science 323.5911 (2009): 240-244.

11. Bellon M R and van Etten J. "Climate change and on-farm conservation of crop landraces in centres of diversity". In M. Jackson, B. Ford-Lloyd, and M. Parry (Eds.), Plant genetic resources and climate change. (2014): 137-150.

12. Bellon MR., et al. "Assessing the vulnerability of traditional maize seed systems in Mexico to climate change". Proceedings of the National Academy of Sciences of the United States of America 108 (2011): 13432-13437.

13. Berry JA and Bjorkman 0. "Photosynthetic response and adaptation to temperature in higher plants". Annual Review of Plant Biology 31 (1980): 491-543.

14. Bird RMK. "A remarkable new teosinte from Nicaragua: growth and treatment of progeny". Maize Genetics Cooperation Newsletter 74 (2000): 58-59. 
15. Bolanos J and Edmeades GO. "Eight cycles of selection for drought tolerance in lowland tropical maize. I. Responses in grain yield, biomass, and radiation utilization". Field Crops Research 31 (1993): 233-252.

16. Brush SB. "Farmers' Rights and genetic conservation in traditional farming systems". World Development 20 (1992): 16171630.

17. Burke MB., et al. "Shifts in African crop climates by 2050, and the implications for crop improvement and genetic resources conservation". Global Environmental Change 19.3 (2009): 317 325 .

18. Cabrera-Bosquet L., et al. "Water and nitrogen conditions affect the relationships of D13C and D180 with gas exchange and growth in durum wheat". Journal of Experimental Botany 60 (2009a): 1633-1644.

19. Cabrera-Bosquet L., et al. "Oxygen isotope enrichment (D180) reflects yield potential and drought resistance in maize". Plant, Cell and Environment 32 (2009b) 1487-1499.

20. Camacho Villa T., et al. "Defining and identifying crop landraces". Plant Genetic Resources: Characterisation and Utilisation 3 (2005): 373-384.

21. Campos H., et al. "Improving drought tolerance in maize: a view from industry". Field Crop Research 90 (2004): 19-34.

22. Chauhan BS., et al. "Global warming and its possible impact on agriculture in India”. In Advances in agronomyedited by D. L. Sparks 123 (2017): 65-121.

23. Choudhary M., et al. "Harnessing Crop Wild Relatives for Crop Improvement". LS: International Journal of Life Sciences 6.2 (2017): 73-85.

24. Choudhary M., et al. "QTLian breeding for climate resilience in cereals: progress and prospects". Functional and Integrative Genomics 9 (2019): 685-701.

25. Commuri PD and RD Jones. "High temperatures during endosperm cell division in maize: A genotypic comparison under in vitro and field conditions". Crop Science 41 (2001): 1122-1130.

26. Dyer GA and Taylor JE. "A crop population perspective on maize seed systems in Mexico". Proceedings of the National Academy of Sciences of the United States of America 105 (2008): 470475 .
27. Easterling BA and Johnson EI. "Conducting qualitative research on parental incarceration: Personal reflections on challenges and contributions". The Qualitative Report 20.10 (2015): 1550-1567.

28. Easterling W., et al. "Food Fibre and Forest Products". In climate Change (2007): Impacts, Adaptation and Vulnerability. Pp 273Y313, Cambridge University Press, Cambridge, UK (2007).

29. Edmeades GO., et al. "Selection improves drought tolerance in tropical maize populations. 1. Gains in biomass, grain yield and harvest index". Crop Science 39 (1999): 1306-1315.

30. Engelen-Eiges G., et al. "DNA endoreduplication in maize endosperm cells: the effect of exposure to short-term high temperature". Plant Cell and Environment 23 (2000): 657-663.

31. Eveson RE and Gollin D. "Assessing the impact of the green revolution, 1960Y2000". Science 300 (2003): 578Y672.

32. Fedoroff NV., et al. "Radically rethinking agriculture for the 21st Century". Science 327 (2010): 833Y834.

33. Grant RF., et al. "Water deficit timing effects on yield components in maize". Agronomy Journal 81 (1989): 61-65.

34. Harlan J. "Our vanishing genetic resources". Science 188 (1975): 618-621.

35. Heisey PW and GO Edmeades. Maize production in droughtstressed environments: Technical options and research resource allocation. Part 1 of CIMMYT 1997/1998 world facts and trends; Maize production in drought-stressed environments: Technical options and research resource allocations. CIMMYT, Mexico D.F., Mexico. in the Central Valleys of Oaxaca, Mexico. World Development 35 (1999): 1579-1593.

36. Iltis HH and Benz BF. "Zea nicaraguensis (Poaceae), a new teosinte from Pacific coastal Nicaragua". Novon 10 (2000): 382390.

37. Jarvis A., et al. "The effect of climate change on crop wild relatives". Agriculture, Ecosystems and Environment 126 (2008): 13-23.

38. Jones HG., et al. "Thermal infrared imaging of crop canopies for the remote diagnosis and quantification of plant responses to water stress in the field". Functional Plant Biology 36 (2009): 978-989. 
39. Kaur K. "Mapping of QTLs for drought tolerance component traits in maize (Doctoral dissertation, Punjab Agricultural University, Ludhiana)" (2007).

40. Larkindale J., et al. "Plant responses to high temperature". In MA Jenks, PM Hasegawa, eds, Plant Abiotic Stress. Blackwell Scientific Publications, Oxford (in press) (2005).

41. Li C., et al. "Numerous genetic loci identified for drought tolerance in the maize nested association mapping populations". BMC Genomics 17.1 (2016): 894.

42. Lobell DB and CB Field. "California perennial crops in a changing climate". Climatic Change 109 (2011): S317-S333.

43. Mano Y., et al. "Identification of QTL controlling adventitious root formation during flooding conditions in teosinte (Zea mays ssp. huehuetenangensis) seedlings". Euphytica 142 (2005) 33-42.

44. Mano $\mathrm{Y}$ and Omori F. "Breeding for flooding tolerant maize using 'teosinte' as a germplasm resource". Plant Root 1 (2007): 17-21.

45. Marti J., et al. "Can wheat yield be assessed by early measurements of normalized difference vegetation index?" Annals of Applied Biology 150 (2007): 253-257.

46. Mercer J., et al. "Integrating indigenous and scientific knowledge bases for disaster risk reduction in Papua New Guinea". Geografiska Annaler: Series B, Human Geography 91.2 (2009): 157-183.

47. Mercer KL., et al. "Climate change and the transgenic adaptation strategy: smallholder livelihoods, climate justice, and maize landraces in Mexico". Global Environmental Change 22.2 (2012): 495-504.

48. Monjardino P., et al. "Heat stress effects on protein accumulation of maize endosperm". Crop Science 45 (2005): 1203-1210.

49. Ray JD., et al. "Introgressing root aerenchyma into maize". Maydica 44 (1999): 113-117.

50. Ruiz Corral JA., et al. "Climatic adaptation and ecological descriptors of 42 Mexican maize races". Crop Science 48.4 (2008): $1502-1512$.
51. Schoper JB., et al. "Maize pollen viability and ear receptivity under water and high temperature stress". Crop Science 26 (1986): 1029-1033.

52. Salvi S and Tuberosa R. "The crop QTLome comes of age". Current Opinion in Biotechnology 32 (2015): 179-185.

53. Singletary GW., et al. "Effects of heat stress on enzyme during grain filling in maize: Effects on carbohydrate storage and metabolism". Australian Journal of Plant Physiology 21 (1996): 829-841.

54. Stone P. "The effects of heat stress on cereal yield and quality". In: Basra, A.S. (Ed.), Crop Responses and Adaptation to Temperature Stress. Food Products Press, Binghamton, NY (2001): 243-291.

55. Thornton PK., et al. "Spatial variation of crop yield response to climate change in East Africa". Global Environmental Change 19.1 (2009a): 54-65.

56. Trachsel S., et al. "Identification of QTL for early vigor and stay-green conferring tolerance to drought in two connected advanced backcross populations in tropical maize (Zea mays L.)". PloS one 11.3 (2016): e0163400.

57. Varshney RK., et al. "Genomics-assisted breeding for crop improvement". Trends in Plant Science 10 (2005): 621-630.

58. Walker JM. "One-degree increments in soil temperatures affect maize seedling behavior". Soil Science Society of America Processing (1969).

59. Wani SH., et al. "Marker-assisted breeding for abiotic stress tolerance in crop plants". In Biotechnologies of Crop Improvement 3 (2018): 1-23.

60. Wang N., et al. "Identification of loci contributing to maize drought tolerance in a genome-wide association study". Euphytica 210.2 (2016): 165-179.

61. Watts WR. "Leaf extension in Zea mays. I. Leaf extension and water potential in relation to root-zone and air temperature". Journal of Experimental Botany 23 (1972): 704-712.

62. Weaich K., et al. "Modeling preemergent maize shoot growth. II. High temperature stress conditions". Agriculture Journal 88 (1996): 398-403. 
63. Whitford R., et al. "Hybrid breeding in wheat: technologies to improve hybrid wheat seed production". Journal of Experimental Botany 64 (2013): 5411-5428.

64. Zhao X., et al. "Mapping QTLs and meta-QTLs for two inflorescence architecture traits in multiple maize populations under different watering environments". Molecular Breeding 37.7 (2017): 91.

\section{Assets from publication with us}

- Prompt Acknowledgement after receiving the article

- Thorough Double blinded peer review

- Rapid Publication

- Issue of Publication Certificate

- High visibility of your Published work

Website: www.actascientific.com/

Submit Article: www.actascientific.com/submission.php

Email us: editor@actascientific.com

Contact us: +919182824667 